\title{
Contextualism in normative political theory and the problem of critical distance
}

\author{
Lægaard, Sune
}

Published in:

Ethical Theory and Moral Practice

DOI:

10.1007/s10677-019-10026-6

Publication date:

2019

Document Version

Peer reviewed version

Citation for published version (APA):

Lægaard, S. (2019). Contextualism in normative political theory and the problem of critical distance. Ethical Theory and Moral Practice, 22(4), 953-970. https://doi.org/10.1007/s10677-019-10026-6

\section{General rights}

Copyright and moral rights for the publications made accessible in the public portal are retained by the authors and/or other copyright owners and it is a condition of accessing publications that users recognise and abide by the legal requirements associated with these rights.

- Users may download and print one copy of any publication from the public portal for the purpose of private study or research.

- You may not further distribute the material or use it for any profit-making activity or commercial gain.

- You may freely distribute the URL identifying the publication in the public portal.

Take down policy

If you believe that this document breaches copyright please contact rucforsk@kb.dk providing details, and we will remove access to the work immediately and investigate your claim. 


\title{
Contextualism in normative political theory and the problem of critical distance
}

Sune Laegaard, Department of Communication and Arts, Roskilde University,Denmark, laegaard@ruc.dk

The official version of this paper is under publication in Ethical Theory and Moral Practice, DOI: 10.1007/s10677-019-10026-6, Link to journal webpage: https://ink.springer.com/journal/10677

\begin{abstract}
Political theory is contextualist when factual claims about context are part of the justification of normative political judgments. There are different kinds of contextualism depending on whether context is relevant for the formulation and justification of political principles (methodological contextualism), whether principles themselves are contextually specific (theoretical contextualism), or whether context is only relevant for the application of principles. An important challenge to contextualism is the problem of critical distance: how can theories ensure a critical perspective if facts about the context to be evaluated are also part of the justification for the normative judgments? Tariq Modood and Simon Thompson have defended what they call iterative contextualism, which combines elements of all three kinds of contextualism in an attempt to avoid the problem of critical distance. The present paper discusses Modood and Thompson's iterative contextualism and whether it manages to avoid the problem of critical distance.
\end{abstract}

\section{Keywords}

Contextualism, political theory, methodology, justification, secularism 


\section{Introduction}

Political theory is contextualist when factual claims about the context of a case are part of the justification of normative political judgments about this case. Given this wide definition of contextualism, most theories in political theory are contextualist in some sense and it would not make sense to argue for or against contextualism per se. There are, however, different kinds of contextualism depending on whether context is relevant for the formulation and justification of political principles (methodological contextualism), whether principles themselves are contextually specific (theoretical contextualism), or whether context is relevant for the application of principles. There is reason to consider contextualism in more detail, since some versions of contextualism face an important challenge, namely the problem of critical distance. Given that the point of political theory is to justify normative judgments about specific cases, the problem is how theory can offer a critical perspective on a case if facts about the context of the case are also part of the justification for the normative judgment. Tariq Modood and Simon Thompson have recently defended what they call iterative contextualism, which combines elements of all three kinds of contextualism in an attempt to avoid the problem of critical distance. The aim of this paper is to consider which forms of contextualism face the problem of critical distance and to evaluate whether Modood and Thompson's iterative contextualism provides an adequate answer to it.

I use Cécile Laborde's recent formulation of a principle of secularism as civic inclusiveness, which according to Laborde is "singularly context-dependent", to illustrate the difference between kinds of contextualism and how they give rise to different versions of the problem of critical distance. This principle stands in need of specification in order to explain why it has the implications Laborde thinks it has for specific cases such as the Lautsi case regarding mandatory crucifixes in Italian schools and the Swiss minaret ban. This specification will look different, depending on which form of contextualism is at play. On this basis, I consider whether Modood and Thompson's iterative contextualism succeeds in avoiding the noted versions of the problem of critical distance. I argue that iterative contextualism instead faces different problems (the problem of generality and the problem of equilibrium). The aim of my discussion is not, however, to reject contextualism in general or Modood and Thompson's iterative version in particular. Given 
my general definition of contextualism, any plausible theory arguably has to be contextualist in one or more senses. My aim is rather to make the differences between forms of contextualism clear and to use the discussion of Modood and Thompson's response to the problem of critical distance to articulate some general desiderata for any contextualist theory. My claim here is that, even if any plausible theory has to be contextualist, it has to provide answers to not only the problem of critical distance but also the generality and equilibrium problems, and that these answers cannot themselves be contextualist in nature. The paper thus aims to contribute with constructive criticism of contextualism showing the limits of contextualist reasoning, which contextualist political theorist have to be aware of and reflect upon.

The structure of the paper is as follows. I first present contextualism and distinguishes between different senses of contextualism in normative political theory. I also note how the issue about contextualism is different from other issues about the relation between facts and norms in political theory. I then use Laborde's secularism as civic inclusiveness as an illustration of different kinds of contextualism. Following that, I present the problem of critical distance and Modood and Thompson's proposal for an “iterative contextualism" supposed to be able to avoid this problem. On this basis, I return to Laborde's theory, which stands in need of specification in order for us to be able to assess and apply it. I show how iterative contextualism might provide a model for such a specification. Iterative contextualism faces other problems of its own, however, which I present in the final section.

\section{Contextualism}

Contextualism in normative political theory is a family of views holding that factual claims about the context of a case are part of the justification of normative political judgments about this case. It differs from other forms of contextualism, e.g. those that invoke context as important for explanation of political behavior or as necessary for the interpretation and exegesis of historical texts, in being a part of normative political theory. I take normative political theory to be concerned with normative judgements of an evaluative or prescriptive nature, e.g. about the justice of institutions, the legitimacy of decisions, or with which policies it would be 
best to adopt on a certain issue. I further take political theory to require systematic justification for such judgments. Contextualism in normative political theory accordingly says that context matters for justification of normative judgments.

This initial specification allows for many different forms of contextualism. There are different views about which kinds of context, and accordingly which kinds of factual claims, are relevant for the purpose of normative justification. There are furthermore different views about which kind of role context plays in normative justification. In this paper, I will focus on the most important forms of contextualism regarding this second question. ${ }^{1}$

Given that normative political theory is concerned with systematic justification for normative judgments, one can distinguish between different kinds of contextualism in normative political theory on the basis of which part of such normative justification involves appeal to context. A widely accepted view of normative justification is that, in order for it to be systematic and hence qualify as a form of political theory, the justification of particular judgments must somehow be based on, derive from or otherwise appeal to more general political principles, e.g. principles of distributive justice, procedural legitimacy or of the common good. Although there are some forms of political theory that eschew appeal to general principles, which I will touch on below, most forms of political theory - including most forms of contextualism - do in some

\footnotetext{
${ }^{1}$ I take it that the answer to the question about the role of context will have implications for answers to the first question about what the relevant kinds of contextual facts are. I will therefore proceed without attempting to define "context", although this might seem unsatisfactory. Different contextualist theories include different kinds of factual claims, some focus on facts about actually established laws or institutions, other about existing social structures, other again the facts about the history of these. The contextualism proposed by Modood and Thompson, which I focus on below, focuses on contextual norms and values, e.g. as informing established laws. For this reason, factual claims about local norms will be in focus below. But this should not be taken to mean that all forms of contextualism share this focus.
} 
way involve reference to principles. We can therefore provide a rough initial characterization of forms of contextualism by pointing to different roles context can play in justification of normative judgments. ${ }^{2}$

For present purposes, it will suffice to distinguish three roles:

1) Input concerns the formulation and justification of principles: This part of political theory is concerned with articulating, defending, modifying and criticizing potential principles. Context can play a role here as a source of principles (if a norm operative in a given context is adopted by the theorist as a principle) or as a resource against which proposed principles are tested in various ways (if principles are taken to be justified to the extent that they fit with norms in specific contexts). Context can thus both provide reasons for or against adopting principles (positive and negative justification, respectively).

2) Content concerns the principles themselves: This part of political theory consists in the actual specification of what the principles are, i.e. the categories they rely on and the scope within which they hold. Context can play a role here if the formulation of the principle itself makes reference to a particular context (e.g. special duties holding among members of a specific group, e.g. a specific nation or religious community) or to categories that only obtain in very specific contexts (e.g. within a certain type of association, e.g. political parties in liberal democracies, or an arguably sui generis political organization like the European Union). ${ }^{3}$

\footnotetext{
${ }^{2}$ There are other roles for context to play in political theory than these, e.g. as a source of problems (Lægaard 2015: 262-63; Lægaard 2016: 10-11). In this paper, however, I focus on the roles related to the justification of normative judgments about cases, since these are the ones potentially giving rise to the problem of critical distance.

${ }^{3}$ Even if a principle is formulated in a way making reference to a particular context or relying on categories that only obtain in particular contexts, it might still be formally universal. This does not matter a lot, however, if the contextual elements limit the material scope. Theoretical contextualists are generally concerned with the material substance of principles rather than whether they can be given a formally universal formulation or not.
} 
3) Output concerns the application of principles to particular cases in order to justify specific normative judgments about these cases: This part of political theory takes certain principles as premises in order to provide systematic arguments about specific cases, e.g. a specific law or institution. Context can play a role here in order to connect general principles to specific cases, e.g. as empirical premises about the case that provides the link between a general normative principle and the case necessary for the argument to be valid.

I have elsewhere provided characterizations of different kinds of contextualism that correspond to these different roles:

- Methodological contextualism: This is the view that political theorists use context to illustrate potential principles and their implications in order to be able to argue for or against a proposed principle by critically assessing it in light of its implications for particular cases (Lægaard 2015: 264; Lægaard 2016: 7-8). This is called methodological contextualism because it concerns the process of formulating and justifying principles. It accordingly concerns the input role.

- Theoretical contextualism: This is the view that principles are contextually specific, which means that - at least for a given subject-matter - there are not context-independent principles that hold across several different contexts (e.g. Lægaard 2015: 269; Lægaard 2016: 6). This is called theoretical contextualism because it concerns the content of principles, which are central to what makes something political theory, and accordingly it pertains to the content role. There are however, different versions of theoretical contextualism depending on whether context-specificity holds for all or only for some principles. In the latter case, there could still be other principles that are general across contexts. In the former case, it is a general view that all principles are context-specific and hence that there are no context-independent principles, which amounts to a rejection of generalism. The latter view can be called particularist contextualism (Lægaard 2016: 14-16).

- Applicatory contextualism: This is the view (widely shared in applied ethics and political theory) that context co-determines the implications of general principles for particular cases since arguments for normative judgments require both normative premises in the form of general principles and 
empirical premises in the form of factual claims about specific cases that connect general principle to cases (Lægaard 2015: 266; Lægaard 2016: 13). This is called applicatory contextualism because it concerns the application of general principles to specific cases and accordingly the output role. Note, however, that the idea that application requires both a general principle and factual claims about the specific case does not in itself say anything about how general the principle to be applied is. The application model can therefore hold even if the principle in question is context-specific, as long as it makes sense to distinguish between the wider context and the specific case. Also, the model does not necessarily say anything about the nature of application, e.g. whether it has to take the form of deductively valid arguments or whether there can be other modes of application.

Given that these different types of contextualism concern different roles, they do not necessarily rule each other out and it is quite possible to combine them in various ways. One might for instance combine methodological and applicatory contextualism. This is in fact a quite standard position in normative political theory, which is for instance exemplified by Rawlsian reflective equilibrium methodology (Rawls 1999). One might also combine all three kinds of contextualism, at least for some versions of theoretical contextualism. My point in distinguishing these roles is to show that context may matter in different ways and that most theories will often involve some form of contextualism (even pure Kantian moral theory seems to involve a kind of applicatory contextualism); but which way context matters make a difference for the resulting theory. The typology is thus analytical rather than descriptive of specific contextualist theories in their (often complex) entirety. The point of such an analytical typology is to help identify when the problem of critical distance, to which I return later, arises.

Particularist contextualism is a special case, which can be understood as rejecting the distinction between different roles (Lægaard 2016: 14-16). Particularism rejects the very idea that political theory is about general principles, so in that sense my distinction between roles does not apply at all according to particularism. According to particularism, the three roles collapse into one, since there is no difference between articulating the normative judgment regarding a particular case and justifying it. 
Before proceeding, it is interesting to clarify the relationship between contextualism in the noted senses and other debates about the relationship between factual and normative judgements. Contextualism is a version of the general view that political theory is fact-sensitive. Applicatory contextualism is a (quite common) version (albeit not the only one) of the view that facts enter into the determination of the implications of principles. As such, the resulting normative judgments are fact-sensitive. This is distinct, however, from the further claim that principles are fact-sensitive (cf. Cohen 2008). Commitment to applicatory contextualism is compatible with a rejection of the fact-sensitivity of principles. Theoretical and methodological contextualism, on the other hand, are versions (again, not the only ones) of the view that facts enter into the determination of principles, although this fact-sensitivity is different depending on whether it concerns the input or content role.

The contextualism issue is, however, different from other prominent issues about the relation of facts to political theory. One such issue is the question about whether and how "ought implies can" and issues about feasibility. "Ought implies can" is most plausibly understood as a constraint on normative judgments requiring agents to act in certain ways - if an action is impossible for the agent in question to perform, the principle says that the agent cannot be duty-bound to so act and therefore is not morally blameworthy for not doing so. "Ought implies can" therefore only claims that facts are relevant to what I have called the output role and only in a limiting capacity where they constrain possible duty ascriptions. As such, "ought implies can" is different from applicatory contextualism, which also pertains to the output role, but according to which factual claims about the context provide part of the positive reasons for normative judgments.

Considerations about feasibility can be understood as a version of the "ought implies can" principle, but there might also be differences. One difference might be that, where the "ought implies can" principle only says that an action cannot be required if it is strictly impossible to perform, feasibility constraints can expand the modalities that are claimed to be relevant to normative judgments. So even though a policy is not strictly impossible to carry out, it might be unfeasible if it is very difficult, e.g. because its success requires people to be motivated in a way they usually are not, or because it involves costs in other 
respects. If the costs in question are themselves normatively relevant, this is better understood as a matter of there being countervailing normative reasons that in some cases might outweigh reasons deriving from a principle in an all-things-considered judgment. If the costs are not themselves normatively relevant but simply are factual obstacles, e.g. because it is not in the interest of some political actors to incur such costs, then one can say that a policy may be unfeasible even though it is not strictly impossible. This way of understanding feasibility constraints still only pertains to the output role and only take facts to be relevant in a limiting capacity (Lægaard 2016: 13-14).

Feasibility can also, however, be understood as not only pertaining to the limitation of available normative judgments as output. It might also be a consideration for deciding which principles are correct in the first place. As such, feasibility would take facts to be relevant not only as limiting output but also as considerations limiting which principles can be justified as input. This might be one way of understanding Rawls's classic concern with "the strains of commitment", according to which parties to the contract will avoid choosing principles they can adhere to only with great difficulty (Rawls 1999: 153-54). Nevertheless, even if one understands feasibility constrains to apply not only to output but also to input, they still only make facts relevant as limitations on permissible principles. As such, feasibility differs from contextualism properly understood, which takes facts to be part of what positively justifies principles. ${ }^{4}$

The issue about contextualism is also different from the issue about ideal versus non-ideal theory. The original Rawlsian understanding of ideal theory is as co-called strict compliance theory, which

\footnotetext{
${ }^{4}$ Modood and Thompson (2018: 351) understand practices, structures and institutions characterizing a particular context at a particular time as "practical constraints which concern the feasibility of different courses of action", which should be "borne in mind when seeking to reach an all-things-considered judgement about what should be done in each particular situation". These formulations suggest that feasibility pertains to output (cf. the focus on "courses of action"). So even though facts about the context are relevant for the feasibility of courses of action which political theorists have to bear in mind when applying their principles, this does not amount to a properly contextualist element of their view. It is rather simply an additional way in which context may limit judgments.
} 
assumes that citizens governed by a conception of justice have an effective sense of justice and therefore generally act in accordance with the principles of justice (Rawls 1999: 8, 125-126, 215). Rawls takes this assumption to be relevant when the parties in the original position contemplate which principles of justice to choose, i.e. as part of the input role. Once principles are chosen, however, the assumption can be relaxed for the purpose of the adaptation or modification of the principles of justice to less optimal circumstances, i.e. as part of the output role. Here, Rawls distinguishes between two types of non-ideal theory, one about natural limitations and historical contingencies, the other about partial compliance (Rawls 1999: 8, 216-217). So non-ideal theory in the Rawlsian sense primarily plays an output role where principles are applied and it functions much like feasibility constraints in that it directs us to consider what the best implementation of ideal principles is under non-ideal circumstances.

This does not mean, however, that non-ideal theory and contextualism are the same things. Ideal theory can still take contextual facts into account, as long as they are compatible with strict compliance, and not all of the non-ideal facts that are taken into account to limit output need be contextually specific. It is in principle possible to do very context-specific ideal theory, i.e. political theory concerned with articulating principles for a very specific context, but where this context is idealized for the purpose of deciding what the correct principles are. It is also possible to do very non-contextual non-ideal theory, e.g. if the non-ideal circumstances taken into account to limit output are general human shortcomings. Most contextualists happen to conduct political theory more reminiscent of Rawlsian non-ideal theory, but there is not a necessary connection between the two and they are basically about different things.

\section{An illustration of contextualism: Laborde's secularism as civic inclusiveness}

In this section, I will present a specific element of Cécile Laborde's recent theory of secularism in order to use it to exemplify different senses of contextualism. The reason for using Laborde's theory as an illustration is, first, that she herself writes that this part of the theory is "singularly context-dependent". A second reason is that it is actually unclear in which sense it is contextualist, so it can be used to illustrate the difference 
between different senses of contextualism. Finally, since the aim of her discussion is something else, Laborde herself only exemplifies this part of her theory quite briefly and without explaining in any detail why it has the implications she takes it to have. It is therefore in need of further specification if it is to be assessed and applied to new cases. This kind of specification will look quite different depending on in which sense the theory is contextualist, so it also provides a way of exemplifying some of the problems facing contextualist theories that I will focus on in the second half of the paper.

Cécile Laborde's Liberalism's Religion (2017) is concerned with how liberal political philosophy understands religion. Laborde's main claim is that there is not one single category of religion that is constant across different debates about religion within liberal political philosophy. She proposes to disaggregate the concept of religion in three dimensions that are relevant to understanding secularism as a minimal normative requirement of liberal legitimacy. For present purposes, I will focus on the dimension of religion concerned with vulnerability. Laborde's claim here is that for some purposes religion is analogous to other social identities like race that can be the basis of discriminatory treatment. A liberal state should secure equal rights and non-discrimination on religious grounds. Even then, purely symbolic forms of establishment can trigger issues of civic inclusiveness. Laborde therefore formulates her second principle of liberal minimal secularism that seems relevant for this purpose as follows:

\section{Principle 2 of liberal minimal secularism}

When a social identity is a marker of vulnerability and domination, it should not be symbolically endorsed and promoted by the state (Laborde 2017: 137)

Call this principle a version of secularism as civic inclusiveness.

Laborde's principle explicitly appeals to vulnerability and domination as the normatively relevant characteristics. However, the principle is actually an expression of a more fundamental concern:

Symbolic religious establishment is wrong when it communicates that religious identity is a component of civic identity - of what it means to be a citizen of that state -, and thereby deny 
civic status to those who do not endorse that identity, who are then treated as second-class citizens. (Laborde 2017: 135)

For present purposes, the crucial question for such an account are a) when does a state act communicate such a message, and b) what is the standard of equal civic status against which this has to be assessed? Laborde touches on these questions in her elaboration of the view:

The thought is that when the state associates itself too closely with the symbols of the majority, non-adherents are rejected outside the imagined community of citizens. Symbolic establishment is wrong, on this account, when it constitutes and perpetuates social relations of hierarchy, subordination and domination. (2017: 136)

The question is what this standard of civic equality is. Laborde addresses this question thus:

the criterion of civic inclusiveness is singularly context-dependent. But this does not make it fatally indeterminate. The key is to specify which identities are, in particular societies, vulnerable from the point of view of equal citizenship; and which official symbols perpetuate and consolidate these vulnerabilities. $(2017: 138)^{5}$

For present purposes, the question is what it means that this criterion of civic inclusiveness is "contextdependent". Recalling my distinction between roles, contextualism can hold for each of the input, content and output roles in political theory. So which kind of context-dependence might be at play in Laborde's theory?

Initially, it does not seem that Laborde's contextualism is of the methodological kind pertaining to the input role. This is simply because she has formulated and justified her principle, not on the basis of its implications for concrete cases in different contexts, but on the basis of a review of the most

\footnotetext{
${ }^{5}$ It is not clear from the text what Laborde means by writing that the criterion of civic inclusiveness is "singularly" context-dependent, e.g. whether it is uniquely context-dependent relative to other principles or perhaps rather contextdependent in just one dimension or respect.
} 
prominent liberal theories of religion. She offers her principle as a way of capturing a distinct kind of concern with religion in liberal political philosophy. So the principle is not formulated, at least not directly, on the basis of a concern with specific contexts or justified on the basis of its implications for specific contexts. Therefore, Laborde's contextualism does not seem to be of the methodological kind pertaining to the input role.

A more immediately fitting reading is that that Laborde's theory is a form of theoretical contextualism. This would mean that the criterion of civic inclusiveness itself is contextually variable so that equal citizenship and civic status simply mean different things in different societies. This reading is suggested by the quote above as well as by Laborde's remark that "The inclusiveness criterion, then, is of necessity context-dependent." (2017: 142) This would be a version of theoretical contextualism since this would mean that there would be different principles of civic equality for different contexts (e.g. different nation states).

A possible illustration of such a view might be that civility in some countries is taken to require certain kinds of politeness between citizens, e.g. respect for the religious sensibilities of other citizens and consequent non-offensive behavior. In other societies, however, civility means that everybody are equally subjected to satire and ridicule, even if this happens to offend their religious sensibilities. This might be a case where different principles of civic equality hold (here at the individual rather than state level) in different national contexts whose contents are radically different and even contradictory.

A third reading, however, is that Laborde's theory is only contextualist in the applicatory sense relevant to the output role. This would mean that the criterion and standard is context-independent, in the sense that what equal citizenship requires is the same across societies, but that empirical differences between societies make different identities turn out to be vulnerable in different societies. Therefore, a given symbol can turn out to perpetuate civic inequality in one society, whereas a similar symbol may not do so in another society. This is apparently what Laborde thinks when she writes that the wrongness of state-endorsed religious symbols is context-dependent because "social meanings vary from society to society" and "different symbols can have different social meanings in different locations" (2017: 140). Her view is then 
contextualist only in the sense that it varies from context to context a) which groups are vulnerable, and b) which state acts in fact send an exclusionary message. In that case, her normative judgments about symbolic establishment would be a form of applicatory contextualism where context only determines the empirical premises about relevant groups and the meaning of state acts in the argument from non-contextual principles.

This minimally means that apparently similar state acts, e.g. a law regulating religious symbols in public space, can have different social meanings in different contexts. Facts about the (historical, institutional, social etc.) context co-determine the social meaning of a state act performed in this context. It can furthermore be different contextual facts that assume this importance in different cases. In the US context, the particular history of slavery, racial segregation and discrimination for instance plays a special role for the social meaning of state policies, which is absent in some other countries. Policies about the Muslim headscarf might have social meanings in a French context, due to the history of French colonialism in North Africa, the war in Algeria and immigration from these former colonies, that it does not have in Britain, where the colonial and migration history related to South Asia is different, or in other European countries without a comparable history of colonialism and subsequent immigration from former colonies.

Laborde briefly illustrates her principle, but her illustrations seem compatible with either of these readings. The first illustration concerns the Swiss ban on future construction of Islamic minarets, decided in a national referendum in November 2009. Against the point raised by defenders of the ban that it is not a violation of freedom of religion, since minarets are not required for Muslims to practice their religion, Laborde responds that:

Whether or not Muslims value minarets, a public ban on minarets unambiguously sends a message of exclusion to Muslims. What is wrong with the ban is that it places minarets - and, by analogy, Muslims - at the outer border of the imagined national community. (2017: 139)

The second illustration concerns the Lautsi case, in which the Grand Chamber of the European Court of Human Rights in 2011 decided that obligatory crucifixes in Italian public schools did not violate freedom of religion because crucifixes were not religious indoctrination. This decision partly rested on the Italian 
Government's description of crucifixes as cultural and traditional rather than as specific religious symbols. In criticism of this decision, Laborde remarks, "What matters is whether state-enforced symbols are markers of social vulnerability; and culture is not intrinsically more inclusive than religion" (2017: 140).

Laborde's brief remarks regarding the Swiss minaret ban and the Lautsi case focus on the act of the state. They might therefore be read simply as claims that the specific acts of the Swiss and Italian states were exclusionary of Muslims and of non-Christians, respectively. These are claims about the meaning of certain acts in specific contexts, although Laborde does not provide any further backing for her claims and therefore no contextual argument either. Her claim could also be read as saying that public bans on minarets or state-enforced symbols are always exclusionary of religious minorities - but this would not fit well with her remarks elsewhere about the context-sensitivity of civic inclusiveness. However, her claims are equally consistent with the alternative reading according to which the criterion of civic inclusiveness differ from the Swiss to the Italian context.

Having now illustrated different kinds of contextualism by way of Laborde's theory, I will turn to an important challenge to some forms of contextualism and a recent proposal for a kind of contextualism supposed to be able to counter this challenge. I will afterwards return to Laborde's theory to use it again as an illustration of both the problem noted by the challenge and of the alternative form of contextualism.

\section{The problem of critical distance and iterative contextualism}

Normative political theory aims to articulate normative judgments that evaluate and criticize existing institutions, norms and structures. Laborde's criticisms of the Swiss minaret ban and the Italian crucifix requirement are good examples of such normative judgements. Since contextualism takes contextual facts to matter for the purpose of justification of normative judgments, there is a general worry whether contextualism risks having a conservative status quo bias. This might be the case if contextual facts are taken into account in the wrong way, e.g. if facts about the context are taken to be unchangeable even if they are 
not or if existing norms are taken as a point of departure for the articulation of principles even if they might be problematic. ${ }^{6}$ To be critical, contextual principles cannot merely accept the self-conception, established norms or the expressed preferences of an institution or society (Lægaard 2016: 5, 17). Tariq Modood and Simon Thompson articulate this problem as follows:

One frequently voiced criticism of contextualist political theories is that they can do no more than endorse existing political arrangements, no matter how just or unjust these may be (according to some external standard of justice). (Modood and Thompson 2018: 350)

Against this background, Modood and Thompson formulate what is effectively a requirement on any plausible contextualist theory, namely that the contextualist political theorist has to "achieve critical distance from the norms which characterize the contexts with which she is concerned" (Modood and Thompson 2018: 350). Call this the problem of critical distance: Contextualism requires political theorists to take the established norms into account when justifying normative judgments, but in order for principles and normative judgments to have the critical potential expected of normative political theory, the link between them and the contexts they are supposed to be able to evaluate cannot be too close.

There are different ways to secure critical distance. A defensive response to the problem of critical distance is to opt for a modest form of contextualism. In the terms used above, one might do this by limiting the relevance of context to the output role, as applicatory contextualism does. This softens the problem insofar as context then only affects the application of principles, not the principles themselves. This seems to provide a reason for interpreting a view as a form of applicatory rather than theoretical contextualism, if this is possible. As noted, this indeed seems an option in the case of Laborde's secularism as civic inclusiveness. Then it is not the criterion of civic inclusiveness that is context-dependent, but only the empirical facts about which groups are vulnerable in a given context and what state acts express in terms

\footnotetext{
${ }^{6}$ Bernard William's articulate a version of the worry about critical distance in his so-called "critical theory principle" according to which "the acceptance of a justification does not count if the acceptance itself is produced by the coercive power which is supposedly being justified" (Williams 2005: 6).
} 
of inclusion or exclusion of these groups in this context. On that reading, there is no problem of critical distance.

This response will not satisfy most contextualists, however, since it apparently commits one to the existence of context-independent principles, of which theoretical contextualists are critical. So theoretical contextualists like Michael Walzer (1987) and David Miller (2013) seem vulnerable to a dilemma between contextualism and critical distance: they are critical of context-independent principles and therefore want their principles to be context-specific, but at the same time they want their principles to have critical potential. This is difficult if there is a trade-off between critical distance and theoretical contextualism (Lægaard 2016: 17).

Tariq Modood and Simon Thompson (2018) have recently proposed a form of contextualism, which they argue is able to avoid this problem of critical distance. What they call "iterative contextualism" shares elements with each of what I have called methodological, applicatory and theoretical contextualism. The idea is that political theory should start from facts about which norms are established in a certain context. The political theorist interprets the context in order to articulate principles that make best sense of the context and makes the institutions, laws or structures under consideration most justifiable. This is reminiscent of theoretical contextualism insofar as the focus at this stage of iterative contextualism is on formulating contextually specific principles. Iterative contextualism departs from theoretical contextualism, however, in that the political theorist then takes the principle articulated on the basis of the interpretation of one context and applies it to similar cases in new contexts (Modood and Thompson use the example of hatespeech legislation in different national jurisdictions). The political theorist assesses and if necessary modifies the principle on the basis of its implications for the other contexts. This iterative application and modification involves elements of each of what I have called applicatory contextualism and methodological contextualism.

As noted above, such a combination of elements from the different kinds of contextualism is quite possible. Iterative contextualism shares elements from all three kinds of contextualism, and accordingly also resembles theoretical contextualism to the extent that interpretation of established norms provides the 
point of departure for political theory and constrains its outputs. In my terms, it is nevertheless not a type of theoretical contextualism because it operates with general cross-contextual principles. This is precisely why iterative contextualism has the resources for avoiding the problem of critical distance:

what justice requires in each particular context is never a simple and direct function of the norms to be found there. Although principles are generated by a process of reflection on context, because this process is iterated across a number of such contexts, the principle which emerges will be at variance with the set of norms which characterize any one of them (Modood and Thompson 2018: 350)

I will now first provide a possible illustration of iterative contextualism in relation to Laborde's principle and consider whether it is more helpful in understanding the sense in which Laborde's principle could be contextualist. I will afterwards return to iterative contextualism and consider what the price might be for being able to avoid the problem of critical distance in the way Modood and Thompson propose.

\section{Specifying Laborde's principle}

As noted above, Laborde does not explicate the justifications for her normative judgments about the Swiss and Italian cases - she merely uses them as illustrations of the kind of cases to which she takes her principle to apply. It is accordingly not clear exactly what the criterion of civic inclusiveness is, in what sense it is contextual, and why it leads to these judgments in these cases. It is therefore also not immediately possible to apply the principle to new cases. To do so, one would need to specify the criterion of civic inclusiveness further. One would need to know how to operationalize civic inclusiveness and whether it means the same or different things in different contexts.

Iterative contextualism might provide a model for how to specify Laborde's principle and hence a fourth understanding of in which sense it might be contextualist, distinct from the three readings of Laborde's criterion as contextualist considered earlier. Iterative contextualism precisely uses different cases in different contexts to specify general principles. We might plausibly understand Laborde's principle as such a general principle and the Swiss and Italian cases could then serve as context-specific cases that could 
help specify it. In that case, Laborde's theory would be contextualist in a fourth sense - then it would not be a form of theoretical contextualism, since the principle is general across a range of contexts, and it would not only be contextual in the applicatory sense since context also plays an input role in specifying and justifying the principle.

There are different ways of understanding how such an iterative specification of a principle could proceed depending on what is being specified in the process. The specification could concern the normative criterion of the principle, in Laborde's case what civic inclusion centrally requires, or it could concern the kinds of targets it applies to, in Laborde's case which kinds of state acts should be evaluated in terms of the criterion of civic inclusiveness. ${ }^{7}$ Contextual specification of the normative criterion would mean that the same principle could have different implications for otherwise similar targets in different contexts, e.g. it might disallow a constitutional ban on minarets in Switzerland but allow an exactly similar ban in a different society. Contextual specification of the target, on the other hand, would mean that the same normative criterion could apply to different objects in different contexts, e.g. that the principle of civic inclusion applies to how individual citizens dress in one country (say, France) but not in another (say, Britain).

On the iterative model, we would have to identify norms about civic equality already holding in various contexts. We would do this by considering what the established understanding of civic equality is in one case. The norm selected must be one element of a plausible account of the context in question and it should be interpreted in the way that seems most plausible in light of the general principle under consideration (Modood and Thompson 2018: 353-54). So when specifying a general principle of civic equality, the theorist has to be able to identify local norms that can plausibly be interpreted as instances of

\footnotetext{
${ }^{7}$ The target of a principle can further be understood in at least two ways, e.g. as what Abizadeh calls site, which refers to the kinds of objects (actions, rules, or institutions, etc.) appropriately governed by a principles, and scope, which refers to the range of persons who have claims upon and responsibilities to each other arising from a principle
} (Abizadeh 2007: 323). 
such a general principle. In the Italian case, for example, Laborde would have to identify a local norm that takes civic equality to apply to requirements on public schools. It would not do, however, for Laborde's purposes to accept an established Italian norm that links Christian symbols to citizenship - since the norm would then not contribute to the specification of a normative criterion of civic equality that can justify her criticism of the crucifix requirement. The iterative contextualist would rather have to be able to identify an operative norm of civic equality, with the right target but which requires separation of citizenship and religion. Once this norm is found, the iterative contextualist is supposed to use it to specify the criterion of inclusiveness in the general principle.

According to iterative contextualism, this exercise can then be repeated so that the theorist applies the specified principle to a new case, where she identifies a new local norm of civic equality that could plausibly be an instantiation of the general principle and then further specifies the principle on the basis of this new norm. When the principle is adequately specified, it can then be used to criticize laws and practices, e.g. to say that the Swiss ban on minarets is exclusionary in a way that violates the principle of civic equality. It is clear that, if a principle is specified on the basis of a range of contexts, say, on the basis of French, British and American norms, then it will be able to provide a critical perspective on cases in new contexts, say, Italian and Swiss cases. ${ }^{8}$

\footnotetext{
${ }^{8}$ There is also a fifth way of understanding Laborde's theory as contextualist, which is distinct from each of theoretical, applicatory and iterative contextualism. She suggests this reading in a comment about Rawls's political liberalism, which she takes to exhibit "a dualist structure":

on the one hand, it identifies broad conditions of constitutional legitimacy; and on the other, it allows for a high level of context-dependent political inconclusiveness, even about principles of justice (Laborde 2017: 154)

In accordance with this understanding of Rawls, Laborde draws attention to the range and scope of reasonable disagreement about liberal justice. There is a range of permissible understandings of the basic liberal principles of freedom, equality and respect. These principles are general and universal principles, but they allow for different interpretations in different cases. We can accordingly understand Laborde's claims about context-dependence as, on the
} 


\section{Problems for iterative contextualism}

Modood and Thompson are therefore right that an iterative from of contextualism can avoid the problem of critical distance. If you base your general principle on the operative norms in several different contexts, then the resulting principle will be at variance with some (or all) of the norms in question. This apparent solution to the problem of critical distance encounters, however, two questions, faced with which Modood and Thompson make two crucial assumptions that generate new problems for iterative contextualism:

1. Are the norms in the different contexts instances of the same more general principle? Modood and Thompson assume an affirmative answer to this question.

2. What is the appropriate reaction to a mismatch between a general principle and a context-specific norm? Modood and Thompson (2018: 348) assume that the theorist may have reason to revise general principles as a result of the encounter with context-specific norms.

Without an affirmative answer to the first question, there would be no reason to compare the norm in a specific context with a general principle based on interpretations of norms in other contexts. In this case, a mismatch between a general principle (e.g. a principle about public religious symbols based on norms holding in America and France) and a specific norm (e.g. an Italian norm about religious symbols) would not provide any critical distance relative to the norm, since the general principle would then not apply at all to

one hand, not a form of theoretical contextualism, since there are general cross-contextual principles, but, on the other hand, as one where general principles are interpreted and specified for each context. Therefore, the same abstract principle can have different specific meanings for different contexts. This is different from iterative contextualism, which assumes that the general principle is specified on the basis of different contexts, but that there is one best specification that is then valid for all contexts. The fifth reading might instead be understood as a form of contextdependence reminiscent of Andrea Sangiovanni's notion of “mediated deduction", according to which an interpretation of an institution or practice co-determines what higher order normative principles mean in this particular case (Sangiovanni 2016: 20). Such forms of contextualism face other sorts of problems, however (see Lægaard 2019). 
the particular context in question. A contextualist would at least have just as good reason to think that the general principle did not apply to the particular context. Therefore, for the iterative model to function at all, the theorist must be able to determine whether and when a general principle articulated and justified on the basis of norms holding in other contexts applies to a new context. Only then will it actually be relevant to compare the norm identified in this new context with the general principle. What is needed is a metacriterion for determining the appropriate scope of a general principle across contexts.

The second question only becomes relevant if the contextualist can actually justify an affirmative answer to the first question. Assuming an affirmative answer, it is true that a general principle based on other contexts will often be at variance with the norm in a new context (if it is not, this might even be a reason to question whether this really is a case of different contexts). But a mismatch between an applicable general principle and a local norm does not itself tell the theorist how to proceed. A mismatch does not tell the theorist whether to a) adjust the principle to fit the norm, b) adjust the norm to fit the principle, or c) rather decide that the norm is not an instance of the general principle after all (so the mismatch becomes a reason for doubting the assumed affirmative answer to the first question). Even if the theorist sticks to the assumption that the general principle is relevant to the new context (rejecting c), a mismatch does not tell him or her whether to adjust the principle (a) or the norm (b) (Lægaard 2016: 17).

Modood and Thompson seem to assume that new contexts provide reasons for adjusting general principles. But it might just as well provide reasons for retaining a formulation of the principle and use this as a basis for criticizing the norm. One might even think that this is in fact what Laborde does in her criticism of the Italian and Swiss cases. How can a contextualist make this decision? - and how can he or she do so without inviting the objection that the general principle is after all not applicable to the new context? (A more hard-core contextualist might claim that a general principle is not applicable to a new context if the principle is used to criticize a context-specific norm. $)^{9}$

\footnotetext{
${ }^{9}$ Modood and Thompson's iterative contextualism is a version of the strategy of "Widening Contextualism" as an attempt to answer the problem of critical distance (Lægaard 2016: 17-18), which seeks to secure critical distance by
} 
Therefore, while the structure of iterative contextualism provides a way of avoiding the problem of critical distance, this very structure simultaneously leads to two new problems:

1. The generality problem: How to determine when a case is an instance of a general principle based on cases in other contexts?

2. The equilibrium problem: How to determine what the appropriate response is to mismatches between the norms holding in a given context and a general principle based on other contexts?

These two problems are direct effects of the structure of iterative contextualism understood as a view that principles are generated, refined and revised through the examination of a series of particular contexts. This structure itself does not tell the political theorist what the appropriate scope of a general principle is or how to react to mismatches between principle and norm.

Modood and Thompson do, however, invoke other assumptions that might help solve these structural problems. They note that context is also relevant as a source of various constraints. Their third constraint is presented thus:

The third and final sort of constraint which the iterative contextualist imposes on her thinking about justice is normative in character. To accept such a constraint is to give particular consideration to the ideals and values that the people in a particular context presently endorse. These norms are not a practical obstacle to a theorist's desired ideal-like a limited housing stock — but are ideals in their own right (Modood and Thompson 2018: 352)

The normative constraint means that the norms holding in each context should be assigned some extra weight when the theorist considers whether to modify the general principle or to criticize the established norm. As such, the normative constraint might provide a reason for revising the general principle rather than

widening the scope of what is included in the context, thereby providing more resources for criticism. This strategy nevertheless does not provide an answer to the question about how to restore equilibrium between norm and principle. It also risks widening the context so much in the direction of universalism that the view loses its contextualist character. 
requiring revision of the norm when there is a mismatch between established norm and principle. Then the normative constraint provides a solution to the equilibrium problem.

The normative constraint is in principle independent from iterative contextualism understood as a specific structural type of view according to which general principles are formulated on the basis of specific contexts and then modified in light of their implications for other contexts. One can hold such a view without saying that particular consideration should be given to established norms merely because they are established. Established norms can still be points that general principles are evaluated against, without there being a presumption that we should exercise more cautiousness in criticizing the norms in question. Modood and Thompson's normative constraint therefore is a separate normative commitment rather than a necessary element of iterative contextualism understood as a general methodological approach. Commitment to the third constraint then characterizes a specific variant of iterative contextualism.

Unfortunately, the solution of the equilibrium problem by appeal to the normative constraint comes at the price of reinstalling the problem of critical distance. The constraint says that we should assign particular consideration to the norms holding in a given context simply because they are the norms holding in a given context - but this is exactly the conservative status quo bias that motivated the critical distance problem to begin with. In the case of Laborde's theory, this would mean that the appropriate response to the Italian crucifix requirement is more likely not to be one of criticism on the basis that the requirement violates civic equality. Rather, the normative constraint would seem to give the iterative contextualist some reason to revise the principle of civic equality so that Christian symbols can indeed be linked to common citizenship. That would threaten to rob Laborde's principle of its critical potential.

The normative constraint furthermore also risks re-opening the generality problem. This is so because the equilibrium problem only arises once we assume that a general principle applies to a given context. When there turns out to be a mismatch between a general principle and a norm holding in this specific context, the normative constraint tells us to give particular consideration to the norm, which in practice pulls in the direction of modifying the principle rather than criticizing the norm. This modification of the principle thereby ensures equilibrium between principle and norm for this particular context. The 
problem, however, is that this is likely to cause disequilibrium between the modified principle and the norms holding in the other contexts on the basis of which the principle was originally formulated. In Laborde's case, if we revise the principle to fit the Italian norm, then it would certainly no longer fit with French and American norms about civic equality requiring strict separation of religion and citizenship. Achievement of equilibrium relative to one context simultaneously risks generating disequilibrium relative to other contexts. So the normative constraint does not solve the equilibrium problem after all, it merely moves it somewhere else.

The question therefore arises whether it is not really the assumption that the general principle applies to the context in which there are norms holding that require revision of the principle that is wrong. If so, then the normative constraint really amounts to a rejection of generality rather than a solution to the equilibrium problem. By rejecting generality, there is no problem of equilibrium since the principle will then only have to match with the norms holding in one context (unless these are internally contradictory, which Modood and Thompson acknowledge they can be). But then the normative constraint effectively turns iterative contextualism into a non-iterative form of particularist contextualism. However, this was exactly the kind of view that iterative contextualism was supposed to avoid, since it gave rise to the problem of critical distance.

\section{Conclusion}

I have distinguished between different ways in which context may matter to normative political theory and exemplified these by way of interpretations of Laborde's avowedly contextualist principle of civic inclusiveness. Some forms of contextualism give rise to the problem of critical distance, which Modood and Thompson's proposal for an iterative contextualism is supposed to avoid. Iterative contextualism may furthermore provide a distinctive way of understanding how Laborde's principle is contextualist. I have argued, however, that iterative contextualism raises new problems of generality and equilibrium, and that 
Modood and Thompson's normative constraint, which might seem to provide an answer to the equilibrium problem, if it is to offer a solution to the equilibrium problem, reinstalls the problem of critical distance.

The normative constraint is not a necessary part of iterative contextualism. The question therefore is whether a form of iterative contextualism is possible that can include other resources for dealing with the problems of generality and equilibrium. In this paper, I have merely pointed out that any form of iterative contextualism has to provide answers to these problems and that the normative constraint proposed by Modood and Thompson does not do so in a satisfactory manner, since it can only solve the equilibrium problem by simultaneously reinstating the original problem of critical distance.

The structural features of iterative contextualism as formulated by Modood and Thompson leave it as an open question whether general principles should be modified in light of local norms or whether local norms should rather be criticized in light of general principles. To use Laborde's example, if the Italian understanding of civic equality really is that Christian symbols can be part of Italian civic identity, as the Italian government argued, is there any reason to think that this must be right? Even if we were to accept this claim, there must be other points at which local norms should not be taken as a fixed points against which general principles should be modified but rather as a problematic features of a context, which should be criticized in light of a general principle partly drawn from outside the particular context. The equilibrium problem in itself merely points out that there is a decision to be made in these cases. This is a problem because a contextualist seems faced with a dilemma in making this choice. Either the choice is made based on respect for the local norms established in the context, as the normative constraint suggests. But then the problem of critical distance reasserts itself, for why should we respect rather than criticize these local norms? Alternatively, the theorist criticizes the local norms or provide other reasons than the fact that they are established in the context as reasons for adjusting general principles to fit with them. But then the context seems reduced to an object of evaluation on the basis of context-independent principles and reasons.

The motivation behind contextualism often is that theorists want their theories to capture real life controversies, needs and struggles and to speak to people in the midst of actual conflicts. According to 
Geoffrey Brahm Levey, the "Bristol school of multiculturalism", of which he takes Modood to be a prominent member, precisely employs such a "bottom-up" approach:

the Bristol school arrives at multiculturalism by working up from the cultural diversity, identities, difference and consciousness of real life groups rather than 'working down' from a prior commitment to some political values or organizing principle. Nevertheless, in elaborating multiculturalism, the BSM advances a number of political positions which can be thought of as auxiliary principles inferred from its bottom-up, political approach. (Levey 2019: 207)

These principles turn out to include liberal looking principles such as equality, which Levey points out is no surprise, since they are exactly formulated though “iteration of liberal values percolating as a society's public values" (Levey 2019: 214). In other words, Modood's multiculturalism involves liberal principles because it is based on the norms in fact operative in a reasonably liberal society.

One response to the problem of critical distance then is that this contingent presence of certain principles that allow a critical perspective on specific acts, institutions and practices is enough. Even though a political theory articulated on the basis of the operative public values of a different kind of society would be different, and would therefore not be critical of the same things, such a theory would not be appropriate for our societies.

One problem with such a response is that it is vulnerable to changes in society that contextualists themselves would often want to criticize. If both important societal groups and governments become increasingly illiberal, perhaps as a response to each other (as seems to be happening in many Western societies now), the liberalism might soon evaporate from a contextual political theory and then we would lack the resources to be critical of precisely this development.

Another problem with this response is that it in fact seems at odds with Modood and Thompson's own formulation of iterative contextualism, which precisely includes general principles across national societal contexts. Modood and Thompson are apparently not themselves satisfied with the appeal to 
national operative values as a resource for critical distance. This suggests that some degree of universalism is assumed as a point of departure for their iterative contextualism rather than being something that has to be argued for on contextualist grounds. This would fit well with Laborde's principle of civic inclusiveness, which similarly seems to be one she assumes to have priority over the alternative norms proposed in the Italian and Swiss cases. This shows that iterative contextualism must rely on normative commitments, which precede and directs the iterative process (by providing answers to the generality and equilibrium problems). Modood and Thompson's normative constraint is itself an example of such an additional non-contextual normative commitment, so the idea of a pre-contextual normative commitment is not as such foreign to their theory - I have merely argued that it is the wrong kind of normative commitment to solve the equilibrium problem if one wants to avoid the problem of critical distance. The more general lesson is that, in order to avoid the problem of critical distance, contextualism has to rely on meta-criteria for determining the proper scope (degree of generality) and to handle mismatches between contextual norms and general principles (the problem of equilibrium), which cannot in themselves be contextually specific.

\section{References}

Abizadeh A (2007) Cooperation, pervasive impact, and coercion: on the scope (not site) of distributive Justice. Philosophy \& Public Affairs 35(4): 318-358.

Cohen GA (2008) Rescuing justice and equality. Cambridge, MA: Harvard University Press.

Laborde C (2017) Liberalism's Religion. Cambridge, MA: Harvard University Press.

Levey GB (2019) The Bristol school of multiculturalism. Ethnicities 19(1): 200-226.

Lægaard S (2015) Multiculturalism and contextualism: how is context relevant for political theory? European Journal of Political Theory 14(3): 259-276.

Lægaard S (2016) Contextualism in normative political theory. In Thompson WR (Ed) Oxford Research Encyclopedia of Politics. Oxford: Oxford University Press. 
Lægaard S (2019) The role of interpretation of existing practice in normative political argument. Critical Review of International Social and Political Philosophy 22(1): 87-102.

Miller D (2013) Justice for Earthlings. Cambridge: Cambridge University Press.

Modood T and Thompson S (2018) Revisiting contextualism in political theory: putting principles into context. Res Publica 24(3): 339-357.

Rawls J (1999) A Theory of Justice. Revised edition. Cambridge, MA: Harvard University Press.

Sangiovanni A (2016) How practices matter. Journal of political philosophy 24(1): 3-23.

Walzer M (1987) Interpretation and Social Criticism. Cambridge, MA: Harvard University Press.

Williams B (2005) In the Beginning Was the Deed - Realism and Moralism in Political Argument. Princeton: Princeton University Press. 